To be published in: Smith A.D.M., Schouwstra M., de Boer B., Smith, K. The Evolution of Language (EVOLANG 8). World Scientific. pp. 176-183.

\title{
HOW TO IDENTIFY THE UNITS, LEVELS AND MECHANISMS OF LANGUAGE EVOLUTION
}

\author{
NATHALIE GONTIER \\ Marie Curie Outgoing Research Fellow, Division of Paleontology, American Museum of \\ Natural History, New York City, New York \& Centre for Logic and Philosophy of \\ Science, Vrije Universiteit Brussel, Pleinlaan 2, 1050 Brussels, Belgium \\ When evolutionary biologists and epistemologists investigate the evolution of life, they \\ deconstruct the problem into three research areas: they search for the units, levels and \\ mechanisms of life's evolution. Here, it is investigated how a similar approach can be \\ applied to evolutionary linguistics. A methodology is proposed that allows us to identify \\ and further investigate the units, levels and mechanisms of language evolution.
}

\section{Introduction}

Evolutionary epistemologists and biologists agree that life is a highly complex, hierarchically-structured phenomenon. It is too complex to study as a whole, and scholars have therefore found it useful to decompose the study of life's evolution into the search for the units, levels and mechanisms of evolution (Campbell, 1960; Hull, 1980; Lewontin, 1970). Here, it will be argued that evolutionary linguists can benefit from applying a similar approach to the study of the evolution of language.

Many evolutionary linguists agree that language is a highly complex and heterogeneous phenomenon. It can come in both spoken and signed forms and each language is composed of syntax, morphology, semantics, etc. Furthermore, language is anatomically associated with specific morphological structures of the human body (e.g. the supralaryngeal vocal tract, the way we curl our fingers to sign) and brain (Wernicke's and Broca's area). The recognition of this heterogeneity of language as well as the multiplicity of morphological structures that allow us to have language implies that if we want to know how language evolved, we need to study the evolution of all these different elements. Put in evolutionary epistemological jargon, all these elements can be considered as units of language evolution.

Most evolutionary linguists will further acknowledge that language is partly a biological phenomenon and partly a cultural phenomenon. It is a biological phenomenon because of these morphological and neurological language-related structures. It is also a cultural phenomenon that "transcends" our biological 
make-up because newborn infants are unable to develop a full language by themselves. Rather, they learn the language that is spoken in their "language community" through frequent interactions with their parents and peers. In evolutionary epistemological jargon, these neurological, cognitive and sociocultural aspects of language can be considered levels where language evolves.

Finally, many evolutionary linguists also investigate how specific evolutionary mechanisms can explain the evolution of (aspects of) language. Natural selection has been implicated as one of the major evolutionary mechanisms underlying language evolution (Pinker \& Bloom, 1990). But also derivatives of, or alternatives to this mechanism have been associated with the evolution of language. Examples include the Baldwin effect, Ratchet effect, niche construction, etc. In evolutionary epistemological jargon, this implies that the aforementioned evolutionary mechanisms are not only applicable at an evolutionary biological level, but also at a cultural level. We therefore need to examine how the same mechanism can be implicated in both biological and extra-biological phenomena.

In other words, although neither the units and levels of selection debate, nor evolutionary epistemological jargon has been explicitly implemented in evolutionary linguistics, we can understand the research that is being done as exactly such an endeavour of identifying units, levels and mechanisms of language evolution. In fact, a quick dive into the literature allows us to make the following, tentative list of possible units, levels and mechanisms of language evolution (table 1).

Table 1 A tentative listing of different units, levels and mechanisms of language evolution
\begin{tabular}{|l|l|l|}
\hline \multicolumn{1}{|c|}{ Units } & \multicolumn{1}{|c|}{ Levels } & \multicolumn{1}{c|}{ Mechanisms } \\
\hline (Language-related) genes? & Genetic? Neuronal? Brain? & Natural, sexual selection? \\
brain regions? mirror neurons? & Cognitive? The individual/ & Drift? Neural Darwinism? \\
The supralaryngeal vocal & ontogenetic? Linguistic & The Baldwin effect? The \\
tract? home signs? Pointing? & (language in itself)? The group? & Ratchet effect? Niche \\
Idio- socio-dialects? ToM? & Socio-Cultural/ the language & construction? Co- \\
Machiavellian Intelligence? & Community? The species? & evolution? \\
Syntax? Lexicon? Semantics? & \multicolumn{2}{|c|}{} \\
\hline
\end{tabular}

How then can we make the identification of units, levels and mechanisms in evolutionary linguistics more explicit? By introducing the following five clusters of evolutionary epistemological questions: (1) How many units of language evolution are there? (2) How many levels of language evolution are there? (3) Which of these units and levels are necessary and/or sufficient for language to evolve? (4) How do the different units interact, how do the different levels interact, and how do the units and levels in turn interact with each other? Can we order them hierarchically? (5) How many evolutionary mechanisms underlie the evolution of these different units? How do these evolutionary mechanisms work? In the following sections, it will be demonstrated how the implementation of 
these questions can be beneficial to the field of evolutionary linguistics, for it will be shown how they cast new light upon existing problems and help build more complete theories on how language evolved.

\section{Three evolutionary epistemological heuristics of language evolution}

How exactly is it that we can examine a certain trait, feature, event, ... from now on designated as $\mathrm{x}$, as a unit, level or mechanism of language evolution? Three evolutionary epistemological heuristics are provided that answer these questions.

\subsection{The unit heuristic}

How do we know that $\mathrm{x}$ is a unit of language evolution? The heuristic outlined in table 2 suggests that we can identify $\mathrm{x}$ as a unit of language evolution if and only if we can identify a level where $\mathrm{x}$ evolves, and a mechanism according to which $\mathrm{x}$ evolves.

Table 2 Is $\mathbf{x}$ (a feature, trait, space, event, element, ... that is presumed relevant for language evolution) a unit in/of language evolution? read from left to right and top-down

\begin{tabular}{|c|c|c|c|}
\hline$?$ & \multicolumn{3}{|c|}{ Try to prove that it is a unit of language evolution (1 example suffices). Thus go to yes. } \\
\hline \multirow{7}{*}{$\begin{array}{l}Y \\
E \\
S\end{array}$} & \multirow{2}{*}{$\begin{array}{l}\text { Where? At which level } \\
\text { is } x \text { the subject of } \\
\text { language evolution. }\end{array}$} & \multicolumn{2}{|c|}{ Not one level found? $\mathrm{X}$ is not a unit, go to no. } \\
\hline & & $\begin{array}{l}\text { One/multiple level(s)? } \\
\text { (Justifies that } \mathrm{x} \text { is a unit.) }\end{array}$ & $\begin{array}{l}\text { Via which evolutionary } \\
\text { mechanism(s) does x evolve? }\end{array}$ \\
\hline & Since when? & \multicolumn{2}{|c|}{$\begin{array}{l}\text { When did } \mathrm{x} \text { first originate in time and when did it become a unit } \\
\text { of language evolution? }\end{array}$} \\
\hline & $\begin{array}{l}\text { How does this unit } x \\
\text { interact with other }\end{array}$ & \multicolumn{2}{|c|}{$\begin{array}{l}\text { Can this unit be divided into one or several subunits? } \\
\text { If so, are they also units in language evolution? }\end{array}$} \\
\hline & units? & \multicolumn{2}{|c|}{$\begin{array}{l}\text { Can this unit be absorbed into one or several super units? If so, } \\
\text { are they also units in language evolution? }\end{array}$} \\
\hline & $\begin{array}{l}\text { Can this unit also be } \\
\text { regarded as a level } \\
\text { and/or mechanism of } \\
\text { language evolution? }\end{array}$ & \multicolumn{2}{|c|}{$\begin{array}{l}\text { ? \& yes: try and treat the unit as a level and/or a mechanism, go } \\
\text { to level and/or mechanism. }\end{array}$} \\
\hline & Relevance? & \multicolumn{2}{|c|}{$\begin{array}{l}\text { Is the unit } x \text { sufficient and/or necessary for language } \\
\text { evolution? }\end{array}$} \\
\hline \multirow{3}{*}{$\begin{array}{l}\mathrm{N} \\
\mathrm{O}\end{array}$} & \multirow{3}{*}{$\begin{array}{l}\text { Level and/or } \\
\text { mechanism? }\end{array}$} & \multicolumn{2}{|c|}{ ? or Yes: go to level and/or mechanism. } \\
\hline & & \multirow[t]{2}{*}{ No. Window? } & Yes: treat $\mathrm{x}$ accordingly. \\
\hline & & & No: treat $\mathrm{x}$ as irrelevant. \\
\hline
\end{tabular}

In other words, a language unit is defined extensionally and even ostensively, by pointing out the level where, and the mechanism by which, it evolves. This approach differs from traditional approaches in evolutionary epistemology (EE) where units are defined by intrinsic properties such as replication (Dawkins, 1982: 162), interaction (Hull, 1981), or reproduction (Griesemer, 2000). Instead, this paper is written from a pragmatic point of view. It asks how we can identify units, not how we can define them. We can identify units by pointing out the level where they evolve, and the mechanism(s) by which they evolve. 
If one is able to identify $x$ as a unit of language evolution, the heuristic goes on to suggest that we locate the origin of $\mathrm{x}$ in time. Thus, we need to ask when $\mathrm{x}$ originated and when it became part of language evolution. The FOXP2 gene for example (Vargha-Khadem, 2005) is a very old gene and cannot have been a unit of language evolution from its origin in fungi onwards. Nonetheless, at some point in time, it became associated with language.

The problem of hierarchies is tackled by asking if the unit can be subdivided into smaller subunits or embedded into larger superunits. If so, it is recommended that these sub- and superunits are also investigated as possible language evolution units. Because of the fact that no intrinsic definition is given to what a unit might be, we might find it useful to ask whether $\mathrm{x}$, even if it is a unit, might also be a level or even a mechanism of language evolution. Pointing (Leavens, Hopkins, Bard, 2005; Tomasello, 2000), for example, might be a unit of language evolution, but it might also serve as a level where other units such as problem solving evolve.

Once we have considered all these questions, we are much better able to evaluate the importance of $\mathrm{x}$, both in the evolution of language as well as in theorizing on the matter. We examine the importance of $x$ by investigating if the unit is necessary and/or sufficient for language evolution; and necessary and/or sufficient in a theory on language evolution. In other words, the heuristic enables us to evaluate whether more research needs to be conducted or not.

If, on the other hand, we were not able to identify $x$ as a unit of language evolution, we might ask if it is a level or a mechanism of language evolution. If neither, $\mathrm{x}$ might provide us with a window on language evolution. The concept of a window of language evolution was first introduced by Botha (2006). A window is not an actual unit of language evolution but a phenomenon that allows us to draw inferences on how language evolved. Examples given by Botha are current ape signing, Pidgin languages, Creoles and hominin tools.

\subsection{The level heuristic}

How do we know that $\mathrm{x}$ is a level of language evolution? By recursively identifying units that evolve at that level and mechanisms that are active on these units that evolve at this level (table 3). In other words, $x$ is a level of language evolution if and only if one can point out at least one unit that evolves at this level according to one evolutionary mechanism.

Specific to this heuristic is that it asks for the ontological status of the level. Although the primary goal of this article is to pragmatically identify the different units, levels and mechanisms involved in language evolution, we cannot circumvent some metaphysical considerations, especially when we introduce levels of language evolution. If we argue, for example, that there exists a cultural realm, or a linguistic community, we need to investigate how real and material they are, or whether they are merely concepts invoked to facilitate theory 
formation. Anthropologists and linguists have been heavily criticized for assuming that culture or language can form a superorganic structure, especially when it is claimed that this superorganic structure can have an existence independent from this organic level (Sapir, 1917). Of course, neither language nor culture can exist without the presence of real human beings, but neither culture nor language can be reduced to living organisms or even groups. Language and culture can be "carried" by individuals, groups and material things. From an epistemological point of view, it can therefore be useful to postulate the existence of hierarchies, which enable one to analyse the existing data more analytically.

Table 3 Is $x$ ( a feature, trait, space, event, element, ... that is presumed relevant for language evolution) a level in/of language evolution? (read from left to right and top-down)

\begin{tabular}{|c|c|c|c|}
\hline$?$ & \multicolumn{3}{|c|}{ Try to prove that it is a level of language evolution (1 example suffices). Thus go to yes. } \\
\hline \multirow{9}{*}{$\begin{array}{l}\mathrm{Y} \\
\mathrm{E} \\
\mathrm{S}\end{array}$} & \multirow{2}{*}{$\begin{array}{l}\text { How many/which } \\
\text { language units evolve at } \\
\text { this level? }\end{array}$} & \multicolumn{2}{|c|}{$\begin{array}{l}\text { Not one language unit, } \mathrm{x} \text { is not a level of language evolution, go } \\
\text { to no. }\end{array}$} \\
\hline & & \multicolumn{2}{|c|}{ One/multiple unit? (Justifies that $\mathrm{x}$ is a level.) } \\
\hline & $\begin{array}{l}\text { How many evolutionary } \\
\text { mechanisms are active at } \\
\text { (not on) this level? }\end{array}$ & \multicolumn{2}{|c|}{$\begin{array}{l}\text { Equals the question: how many evolutionary mechanisms are } \\
\text { active upon the units that evolve at this level. (testing device) }\end{array}$} \\
\hline & $\begin{array}{l}\text { What is the ontological } \\
\text { status of the level? }\end{array}$ & \multicolumn{2}{|c|}{$\begin{array}{l}\text { The level is an abstract notion that facilitates theory formation/ } \\
\text { an exiting entity. }\end{array}$} \\
\hline & Since when? & \multicolumn{2}{|c|}{$\begin{array}{l}\text { Locate the origin of } \mathrm{x} \text { in time or when it becomes necessary to } \\
\text { invoke } \mathrm{x} \text { as an abstract notion in the theory }\end{array}$} \\
\hline & $\begin{array}{l}\text { How does this level } \mathrm{x} \\
\text { interact with other }\end{array}$ & \multicolumn{2}{|c|}{$\begin{array}{l}\text { Can this level be divided into sublevels? If so, are they also } \\
\text { units in language evolution? }\end{array}$} \\
\hline & levels? & \multicolumn{2}{|c|}{$\begin{array}{l}\text { Can this level be absorbed into superlevels? If so, are they also } \\
\text { units in language evolution? }\end{array}$} \\
\hline & $\begin{array}{l}\text { Can this level also be } \\
\text { regarded as a unit and/or } \\
\text { mechanism of language } \\
\text { evolution? }\end{array}$ & \multicolumn{2}{|c|}{$\begin{array}{l}\text { ? \& yes: try and treat the level as a unit and/or mechanism, go to } \\
\text { unit and/or mechanism. }\end{array}$} \\
\hline & Relevance? & \multicolumn{2}{|c|}{$\begin{array}{l}\text { Is the level x sufficient and/or necessary for language } \\
\text { evolution? }\end{array}$} \\
\hline \multirow{3}{*}{$\begin{array}{l}\mathrm{N} \\
\mathrm{O}\end{array}$} & Unit and/or mechanism? & \multicolumn{2}{|c|}{ ? or Yes: go to unit and/or mechanism. } \\
\hline & & \multirow[t]{2}{*}{ No. Window? } & Yes: treat accordingly. \\
\hline & & & $\mathrm{No}$ \\
\hline
\end{tabular}

It is necessary to ask about the ontological status in order to be able to complete the next step prescribed by the heuristic. This step asks one to locate the origin of the level in time (when it is an existing entity), or to pinpoint when it becomes epistemologically necessary to invoke the level in the theory.

Afterwards, it can be asked if we can subdivide existing levels or embed them into higher levels, and as such one can try to establish ontological or at least epistemological hierarchies. This also allows us to identify new levels.

As was the case with units, it is useful to ask if levels might simultaneously be units or mechanisms of language evolution. Linguistic communities might serve 
as a level for the evolution of idiolects and sociolects, but they can themselves also be units of cultural evolution.

Finally, these research questions will again allow us to more firmly evaluate how necessary and/or sufficient the level is in the evolution of language and in theory formation on the subject.

If, on the contrary, we were not able to identify $x$ as a level of language evolution, we can again recursively ask if $\mathrm{x}$ is either a unit or a mechanism of language evolution or whether it provides a window on language evolution.

\subsection{The mechanism heuristic}

How do we know that $\mathrm{x}$ is a mechanism involved in the evolution of language? $\mathrm{X}$ can be recognized as a mechanism of language evolution if and only if we are able to identify units of language evolution whereupon $\mathrm{x}$ is active, at a certain level of language evolution. If one or multiple such units are identified, $x$ is indeed a mechanism involved in the evolution of language.

Specific to this heuristic is that it subsequently asks how the mechanism works. It is especially here that previous work done in the field of EE can be applied. When faced with questions about how natural selection can be equally applied to biological and extra-biological phenomena, evolutionary epistemologists have found it useful to abstract templates of natural selection. Campbell (1960) argued that natural selection works according to a blind variation and selective retention scheme. This means that each time we can identify something to vary blindly and to be selectively retained, it evolves by means of natural selection regardless of whether that something is a gene, phenotype, cognitive trait, or linguistic feature. Furthermore, the template has heuristic potential: it informs you on how the mechanism works and how we can identify it to be active. Lewontin (1970: 1) abstracted the following logical skeleton of natural selection: phenotypic variation, differential fitness and the heritability of that fitness. Hull (1981) has introduced a template of replicators, interactors and lineages. According to Hull, environmental interaction forms the basis for differential variation (different replicators) and this results in the evolution of different lineages. So far, only Hull's heuristic has been applied to linguistics. Croft (2000) introduced the notion of a lingueme, a linguistic meme (a replicator), that can be understood as a unit of selection. Linguemes are carried by individuals that belong to different speech communities. Their interactions induce variations in the linguemes, and natural selection can subsequently act upon this variation.

Evolutionary mechanisms can be active in many kinds of evolution (the evolution of the brain, the evolution of culture, life, etc.). It is therefore necessary to locate in time when a certain evolutionary mechanism became active, specifically in language evolution.

We can also ask ourselves if the evolutionary mechanism can be divided into submechanisms or embedded into larger supermechanisms. Some authors argue 
that the ratchet effect is a form of evolution by means of natural selection, others argue that it is a different mechanism. In the latter case, we have to demonstrate how it can work independently from natural selection, in the former we need to examine how it is embedded in natural selection.

Table 4 Is $x$ (an evolutionary mechanism, feature, trait, space, event, element, ... that is presumed relevant for language evolution) an evolutionary mechanism involved in/on language evolution? (read from left to right and top-down)

\begin{tabular}{|c|c|c|c|}
\hline ? & \multicolumn{3}{|c|}{$\begin{array}{l}\text { Try to prove that } \mathrm{x} \text { is an evolutionary mechanism involved in language evolution. Thus go } \\
\text { to yes. }\end{array}$} \\
\hline $\begin{array}{l}\mathrm{Y} \\
\mathrm{E}\end{array}$ & \multirow{2}{*}{$\begin{array}{l}\text { On how many units is } \\
\text { this evolutionary } \\
\text { mechanism working? }\end{array}$} & \multicolumn{2}{|c|}{$\begin{array}{l}\text { Not one unit: } \mathrm{x} \text { is not an evolutionary mechanism involved in } \\
\text { language evolution, go to no. }\end{array}$} \\
\hline $\mathrm{S}$ & & \multicolumn{2}{|c|}{$\begin{array}{l}\text { One/multiple unit(s). } \\
\text { (Justifies that } \mathrm{x} \text { is an evolutionary mechanism involved in } \\
\text { language evolution.) }\end{array}$} \\
\hline & $\begin{array}{l}\text { At (not on) how many } \\
\text { levels of language } \\
\text { evolution is this } \\
\text { evolutionary mechanism } \\
\text { active? }\end{array}$ & \multicolumn{2}{|c|}{$\begin{array}{l}\text { Equals the question: the units that are subjected to this } \\
\text { evolutionary mechanism, at how many levels are they } \\
\text { subjected to it? }\end{array}$} \\
\hline & \multicolumn{3}{|c|}{$\begin{array}{l}\text { How does the mechanism work? Which conditions need to be met in order for the } \\
\text { evolutionary mechanism to occur? Answer requires (universal) EE formulas of the } \\
\text { workings of the mechanism. }\end{array}$} \\
\hline & Since when? & \multicolumn{2}{|c|}{$\begin{array}{l}\text { Locate in time when these conditions are met regarding each } \\
\text { unit and each level = when the evolutionary mechanism } \\
\text { became a mechanism involved in language evolution at that } \\
\text { unit and/or level. }\end{array}$} \\
\hline & \multirow{2}{*}{$\begin{array}{l}\text { How does this } \\
\text { mechanism x interact } \\
\text { with other mechanisms } \\
\text { involved in the evolution } \\
\text { of language? }\end{array}$} & \multicolumn{2}{|c|}{$\begin{array}{l}\text { Can this mechanism be divided into sub-mechanism(s)? } \\
\text { (Depends on the presence of subconditions.) If so, are they } \\
\text { also mechanisms of language evolution? }\end{array}$} \\
\hline & & \multicolumn{2}{|c|}{$\begin{array}{l}\text { Can this mechanism be absorbed into a super-mechanism(s)? } \\
\text { (Depends on the existence of a mechanism that allows to } \\
\text { combine different mechanisms into one single mechanism.) If } \\
\text { so, are they also mechanisms of language evolution? }\end{array}$} \\
\hline & $\begin{array}{l}\text { Is this mechanism also a } \\
\text { unit and/or level of } \\
\text { language evolution? }\end{array}$ & \multicolumn{2}{|c|}{$\begin{array}{l}\text { ? \& yes: try and treat the mechanism as a unit and/or level, go } \\
\text { to unit and/or level. }\end{array}$} \\
\hline & Relevance? & \multicolumn{2}{|c|}{$\begin{array}{l}\text { Is the mechanism } \mathrm{x} \text { sufficient and/or necessary for language } \\
\text { evolution? }\end{array}$} \\
\hline \multirow{3}{*}{$\begin{array}{l}\mathrm{N} \\
\mathrm{O}\end{array}$} & Unit and/or level? & \multicolumn{2}{|c|}{ ? or Yes: go to unit and/or level. } \\
\hline & & \multirow[t]{2}{*}{ No. Window? } & Yes: treat $\mathrm{x}$ accordingly. \\
\hline & & & No: treat $\mathrm{x}$ as irrelevant \\
\hline
\end{tabular}

It is also useful to ask ourselves whether the mechanism itself is either a unit or a level of language evolution. Because no intrinsic definition is given with regards to what a mechanism is, such a possibility cannot be excluded a priori.

Finally, answering these questions again allows us to rigorously evaluate the importance of the mechanism in language evolution and theories thereof. If, on the other hand, no unit has been found upon which the mechanism is active at a 
certain level of language evolution, we might examine if $\mathrm{x}$ is a unit or a level of language evolution, or if it provides us with a window on language evolution. If it is neither, $x$ can be treated as irrelevant for the evolution of language.

\section{Conclusion}

At present, scholars are studying a variety of phenomena that are implicated in language evolution. Unfortunately, the nature of these phenomena is not always clear, and neither is it obvious how the different elements under study relate to one another and fit in the puzzle of language evolution. The heuristics provided here allow for the identification, examination and evaluation of the different units, levels and mechanisms of language evolution. As such, they enable us to build unifying theories of language evolution.

\section{References}

Botha, R. (2006). On the Windows Approach to language evolution. Language \& Communication, 26 (2), 129-143.

Campbell, D.T. (1960). Blind variation and selective retention in creative thought as in other knowledge processes. Psychological Review, 67(6): 380400 .

Croft, W. (2000). Explaining language change: An evolutionary approach. Essex: Pearson.

Dawkins, R. (1982). Replicators and vehicles. In N.R. Brandon and R.M. Burian (Eds.) (1984), Genes, organisms, populations (pp. 161-79). Cambridge, MA: MIT Press.

Griesemer J. (2000). Development, culture and the units of inheritance. Philosophy of Science, 67, S348-S368.

Hull, D.L. (1981). Units of evolution. In N.R. Brandon and R.M. Burian (Eds.) (1984), Genes, organisms, populations (pp. 142-159). Cambridge, MA: MIT Press.

Leavens, D.A., Hopkins, W.D. \& Bard, K.A. (2005). Understanding the point of chimpanzee pointing: Epigenesis and ecological validity. Current Directions in Psychological Science, 14 (4), 185-9.

Lewontin, R. (1970). The levels of selection. Annual Review of Ecological Systems, 1, 1-18.

Pinker, S., \& Bloom, P. (1990). Natural language and natural selection. Behavioral and Brain Sciences, 13, 707-784.

Sapir, E. 1917 Do we need a superorganic? American Anthropologist, 19, 441-7.

Tomasello, M. (2000). The cultural origins of human cognition. Cambridge, MA: Harvard University Press.

Vargha-Khadem, F. et al. (2005). FOXP2 and the neuroanatomy of speech and language. Nature Reviews, Neuroscience, 6, 131-138. 